\title{
Association between Attention Deficit Hyperactivity Disorder and lower urinary tract symptoms in children and adolescents in a community setting
}

Mônica Maria de Almeida Vasconcelos ${ }^{1}$, José Murillo Bastos Netto ${ }^{2,3}$, Isaac Eduardo Arana ${ }^{2}$, Isabela Benevenuto Teixeira ${ }^{2}$, Eleonora Moreira Lima ${ }^{1}$, Tânia Antunes Carvalho ${ }^{1}$, José de Bessa Junior ${ }^{4}$, Flávia Cristina de Carvalho Mrad ${ }^{1}$

${ }^{1}$ Departamento de Pediatria, Unidade de Nefrologia, Universidade Federal de Minas Gerais, Unidade de Nefrologia, Belo Horizonte, MG, Brasil; ${ }^{2}$ Departamento de Urologia, Faculdade de Ciências Médicas e da Saúde de Juiz de Fora, Juiz de Fora, MG, Brasil; ${ }^{3}$ Hospital e Maternidade Terezinha de Jesus, Juiz de Fora, MG, Brasil; ${ }^{4}$ Departamento de Urologia, Universidade Estadual de Feira de Santana, BA, Brasil

\section{ABSTRACT}

Introduction: The present study aims to investigate the prevalence of lower tract urinary symptoms (LUTS) and symptoms of attention-deficit/hyperactivity disorder (ADHD) in children and adolescents and their association in a community setting using validated scoring instruments.

Materials and Methods: A cross-sectional study was carried out from February 2015 to December 2019, during which the parents or guardians of 431 children and adolescents from 5 to 13 years of age, attending a general pediatric outpatient clinic were interviewed. Results: The prevalence of ADHD symptoms and LUTS were 19.9\% and 17.9\%, respectively. Of the 82 children and adolescents with ADHD, 28\% (23) had LUTS (OR 2.31, 95\% CI 1.28 to $3.75, \mathrm{p}=0.008$ ). Mean total DVSS score in children in the group of children presenting ADHD symptom was significantly higher than those without ADHD symptom $(10.2 \pm 4.85$ vs. $4.9 \pm 2.95, p=0.002)$. Urgency prevailed among LUTS as the most frequent symptom reported by patients with ADHD symptoms $(p=0.004)$. Analyzing all subscales of the DVSS, the items "When your child wants to pee, can't he wait? "Your child holds the pee by crossing his legs, crouching or dancing?" were higher in those with ADHD symptoms ( $\mathrm{p}=0.01$ and 0.02 , respectively). Functional constipation was present in $36.4 \%$ of children with LUTS and 20.7\% without LUTS (OR 4.3 95\% CI 1-5.3 p=0.001). Conclusion: Children and adolescents with ADHD symptoms are 2.3 times more likely to have LUTS. The combined type of ADHD was the most prevalent among them.

\section{ARTICLE INFO}

José Murillo Bastos Netto

https://orcid.org/0000-0002-9959-6160

\section{Keywords:}

Lower Urinary Tract Symptoms; Child; Attention Deficit Disorder with Hyperactivity

Int Braz J Urol. 2021; 47: 969-79

Submitted for publication:

December 19, 2020

Accepted after revision:

April 06, 2021

Published as Ahead of Print:

May 20, 2021

\section{INTRODUCTION}

Attention-deficit/hyperactivity disorder (ADHD) is the most common neurodevelopmental condition and the second most frequent chronic disorder in children (1-3). ADHD is a clinical diagnosis defined as the occurrence of six or more symptoms both in the state of inattention and in the hyperactive/impulsive state or both, in children under 17 years of age $(2,4)$. Therefore, ADHD was categorized predominantly inattentive, predominantly hyperactive/ impulsive, and combined types, representing 18.3\%, 
8.3\% and 70\% of ADHD children, respectively (4). ADHD is estimated to affect 5 to $10 \%$ of young people worldwide, being more common in boys than in girls (4-7). The Multimodal Treatment Study for ADHD of the Swanson, Nolan, and Pelham version IV (MTA-SNAP-IV) is a valuable instrument for assessing ADHD symptoms severity, besides being helpful for diagnosis purposes $(8,9)$.

Lower urinary tract symptoms (LUTS) are characterized by changes in the bladder emptying and/or storage phase and, if it there is coexistence with functional constipation it is named bladder bowel dysfunction (BBD) $(10,11)$. LUTS is present in about $21.8 \%$ of children and adolescents and girls are predominantly affected (12). The assessment of LUTS includes a careful clinical history and the use of validated questionnaires are helpful in identifying those presenting voiding symptoms. The Dysfunctional Voiding Symptom Score (DVSS) developed by Farhat et al. (13) and validated and adapted to our language and culture by Calado et al., 2010 (14) is considered one of the most commonly used instruments in evaluating LUTS and provides accurate and objective diagnosis of LUTS in children and adolescents.

ADHD and LUTS are not only common disorders in childhood, but also has a high co-existence and interaction with each other (15-18). The prevalence of ADHD in children and adolescents with LUTS is around 42.3\% (19). Therefore, it is necessary to screen for ADHD symptoms in children and adolescents with LUTS (and vice versa) in order to improve treatment and, consequently, quality of life $(11,15,16,19)$.

We hypothesize that, in a general pediatrics clinics population, a significative association between these disorders can also be found. This study aims to investigate the prevalence of LUTS and ADHD symptoms in children and adolescents and the association between these two conditions in our population.

\section{MATERIALS AND METHODS}

A prospective cross-sectional study was carried out from February 2015 to December 2019, during which 431 children and adolescents from 5 to 13 years of age attending a general pediatric outpatient clinic were evaluated. Children and adolescents with moderate to severe intellectual disability of any cause, urogenital malformation or diseases that may impair the function of the bladder or urethral sphincter, were not included in the study. A complete physical exam and standard assessment was performed on all subjects.

The study was approved by Institutional Review Committee (IRB), protocol number 2.625.013, and all parents or guardians of the patients signed an informed consent.

Gestational age at birth (premature less than or equal to 34 weeks, late preterm from 34 to 36 weeks, full-term) was investigated, based on the data recorded on the child's health card. The screening of ADHD symptoms and LUTS was performed through the application of MTA-SNAP-IV (20) and the DVSS (14) questionnaires adapted and validated for the Brazilian population. All interviews were conducted in a confidential environment by pediatricians trained for the application of the instruments, after evaluating the inclusion/exclusion criteria.

The MTA-SNAP-IV (19) includes two subscales with items related to inattention (items 1 to 9) and hyperactivity/impulsivity (10 to 18 ) and uses a 4-point Likert scale, ranging from 0 to 3 (0 Indicating nothing, 1 Just a little, 2 Quite a bit and 3 Very much) (Figure-1). The total score for each dimension is calculated by averaging the items $(8,20)$. If six or more items are marked as quite or very much in subscales 1 to 9 , children or adolescents are considered to have more symptoms of inattention than expected. If six or more items are marked as quite or very much in subscales 10 to 18 , children or adolescents are considered to experience more symptoms of hyperactivity/impulsivity than expected (20). All other individuals with scores below 6 on both subscales were classified as having no ADHD symptoms.

Each subject, with the help of their parents or guardians, answered the ten questions of the DVSS questionnaire (14). The first nine questions assessed daytime incontinence, enuresis, constipation, urgency, voiding frequency, and dysuria. Scores were attributed on a scale of 0 to 3 , with 0 indicating never or almost never, 1 less than half the time, 2 about half the time, and 3 almost every time. Question 10 assesses recent high stress events within the family and answers were dichotomic: yes, for a 
Figure 1 - Multimodal Treatment Study for ADHD of the Swanson, Nolan, and Pelham version IV (MTA-SNAP-IV) adapted from Mattos et al. (20).

\begin{tabular}{|c|c|c|c|}
\hline For each items, check the colune which best describe this child & No At All & \begin{tabular}{l|l} 
Just a Little & Quite a Bit
\end{tabular} & Very Much \\
\hline $\begin{array}{l}\text { 1. Often fails to give close attention to details or makes } \\
\text { careless mistakes in schoolwork or tasks } \\
\text { 2. Often has difficulty sustaining attention in tasks or play } \\
\text { activities } \\
\text { 3. Often does not seem to listen when spoken to directly }\end{array}$ & & & \\
\hline $\begin{array}{l}\text { 4. Often does not follow through or instructions and fails to } \\
\text { finish schoolw ork, chores or duties }\end{array}$ & & & \\
\hline 5. Often has difficulty organizing tasks and activities & & & \\
\hline $\begin{array}{l}\text { Often avoids, dislikes, or reluctantly engages in tasks } \\
\text { requiring sustained mental effort }\end{array}$ & & & \\
\hline $\begin{array}{l}\text { 7. Often loses things necessary for activities (e.g. toys, school } \\
\text { assignments, pencils, or books) }\end{array}$ & & & \\
\hline 8. Often is distracted by extraneous stim & & & \\
\hline 9. Often is forgetful in daily activities & & & \\
\hline 10. Often fidgets with hands or feet or squirms in seat & & & \\
\hline $\begin{array}{l}\text { 11. Often leaves seat in classroom or in other situations in } \\
\text { which remaining seated is expected } \\
\text { 12. Often runs about or climbs excessively in situations in } \\
\text { which it is inappropriate } \\
\text { 13. Often has difficulty playing or engaging in leisure activities } \\
\text { quietly } \\
\text { 14. Often is "on the go" or often acts as if "drives by a motor" }\end{array}$ & & & \\
\hline 15. Often talks excessively & & & \\
\hline $\begin{array}{l}\text { 16. Often blurts out answers before questions have been } \\
\text { completed }\end{array}$ & & & \\
\hline $\begin{array}{l}\text { 17. Often has difficulty aw aiting turns } \\
\text { 18. Often interrupts or intrudes or others (e.g. butts into } \\
\text { conversations/games) }\end{array}$ & & & \\
\hline
\end{tabular}

score of 3 and no for a score of 0 . The cut-off value that indicates the presence of LUTS is $>6$ for girls and $>9$ for boys $(13,14)$ (Figure-2).

The presence of functional constipation was assessed according to the Rome IV criteria (21) (Appendix-1). The Bristol Stool Form Scale modified for children was used to evaluate stool consistency $(22,23)$ (Appendix-2).

Quantitative data was expressed as mean \pm standard deviation (SD) while qualitative variables were expressed as absolute values, percentages, or proportions. The Student t-test or the Mann-Whitney test was used to compare continuous variables, while the categorical variables were compared using the Fisher exact test. Odds ratio and 95\% confidence intervals were used to describe the magnitude of association between LUTS and ADHD symptoms. All tests were 2 -sided with $\mathrm{p}<0.05$ considered statistically significant. Analysis was performed using commercially available statistical software (GraphPad Prism, version 8.03 for Windows, San Diego California USA).

All patients with confirmed LUTS and/ or ADHD symptoms were referred for diagnosis, treatment and follow-up, in specialized outpatient clinics in these disorders.

\section{RESULTS}

Four hundred twelve patients out of the 431 recruited were included in the study. Twelve parents refused to participate, three patients were diagnosed with severe intellectual disability, two had occult spinal dysraphism, and two had hypospadias with surgical complications. The mean age of participants was $7.26 \pm 1.84$ years, being 53.4\% males (220/412).

The overall prevalence of LUTS estimated by DVSS was $17.9 \%$ (74/412). Of those, fifteen (3.6\%) of 
Figure 2 - Dysfunctional Voiding Scoring System (DVSS) adapted from Fahart et al. (13) and Calado et al. (14).

\begin{tabular}{|c|c|c|c|c|}
\hline Over the Last Month & $\begin{array}{l}\text { A lmost } \\
\text { Never }\end{array}$ & $\begin{array}{l}\text { Less } \\
\text { Than } \\
\text { Half the } \\
\text { Time }\end{array}$ & $\begin{array}{l}\text { About } \\
\text { Half the } \\
\text { Time }\end{array}$ & $\begin{array}{l}\text { Almost } \\
\text { Every } \\
\text { Time }\end{array}$ \\
\hline $\begin{array}{l}1 \text { - I have had wet clothes or wet underwear } \\
\text { during the day. }\end{array}$ & 0 & 1 & 2 & 3 \\
\hline 2 - When I wet myself, underwear is soaked. & 0 & 1 & 2 & 3 \\
\hline $\begin{array}{l}3 \text { - I miss having a bow el movement every } \\
\text { day. }\end{array}$ & 0 & 1 & 2 & 3 \\
\hline $\begin{array}{l}4 \text { - I have to push for my bowel movements } \\
\text { to come out. }\end{array}$ & 0 & 1 & 2 & 3 \\
\hline $\begin{array}{l}5 \text { - I only go to the bathroom one or two } \\
\text { times each day. }\end{array}$ & 0 & 1 & 2 & 3 \\
\hline $\begin{array}{l}6 \text { - I can hold onto may pee by crossing my } \\
\text { legs. Squating or doing the "pee dance". }\end{array}$ & 0 & 1 & 2 & 3 \\
\hline 7 - When I have to pee. I cannot wait. & 0 & 1 & 2 & 3 \\
\hline 8 - I have to push to pee. & 0 & 1 & 2 & 3 \\
\hline 9 - When I pee it hurts. & 0 & 1 & 2 & 3 \\
\hline $\begin{array}{l}10 \text { - Parents to answer. Has your child } \\
\text { experienced something stressful like to } \\
\text { example below? }\end{array}$ & NO (0) & YES (3) & & \\
\hline $\begin{array}{l}\text { - New baby } \\
\text { - New home. } \\
\text { - New school. } \\
\text { - School problems. } \\
\text { - Abuse (sexual/physical) } \\
\text { - Some problems (divorce/death). } \\
\text { - Accident/injury. } \\
\text { - Others }\end{array}$ & & & & \\
\hline Total & & & & \\
\hline
\end{tabular}

the 412 had the diagnosis of LUTS prior to the study.

ADHD symptoms were present in 19.9\% (82/412) of children. Of those, a total of 24 patients (5.8\% of 412) had neurodevelopmental disorders symptoms, specifically ADHD and six of them (25\%) had a diagnosis and were receiving treatment with partial response. Of the patients presenting ADHD, $6.1 \%(5 / 82)$ had inattention type, 9.8\% (8/82) hype- ractivity/impulsivity type, and 84.1\% (69/82) combined type of ADHD. When compared by gender, ADHD symptoms were present in 59.7\% (49/82) of the boys (OR 1.4, 95\% CI 1 to 2.9, $\mathrm{p}=0.003$ ).

Of the 82 children and adolescents with ADHD symptoms, 28\% (23/82) had LUTS (OR 2.31, 95\% CI 1.28-3.75, p=0.008), being 56\% (13/23) males. The combined type of ADHD was present in 
91.3\% (21/23) and hyperactivity/impulsivity type in $8.7 \%(2 / 23)$ of the subjects with LUTS (OR 7.5, 95\% CI 1.5-4.78, $\mathrm{p}=0.001)$. None of those with the inattention type presented LUTS (Figure-3).

The average DVSS total score in children and adolescents with ADHD symptoms was significantly higher than in those without $(10.2 \pm 4.85$ and $4.9 \pm 2.95$, respectively, $\mathrm{p}=0.002$ ). Urgency was the most common LUTS, being more frequent in those with ADHD symptoms (65\% versus 35\%, $\mathrm{p}=0.004$ ). When we analyzed the average score of all DVSS subscales, responses to the items "When your child wants to pee, can't he wait?" and "Does your child hold the pee by crossing his legs, crouching or dancing?" were higher in those with symptoms of ADHD ( $\mathrm{p}=0.01$ and 0.02 , respectively) (Table-1).

The overall prevalence of functional constipation (characterized according to the Rome IV criteria) was 31\% (129/412), being 36.4\% (27/74) with LUTS and 20.7\% (70/338) in the ones without LUTS (OR 4.3 95\% CI 1-5.3 p=0.001). Ninety-five percent of the individuals with functional constipation had stool types 1 and 2 of the Bristol Stool Form Scale modified for children. There was no statistical difference in the prevalence of functional constipation between those subjects with and without ADHD symptoms, both associated with LUTS ( $p=0.74)$.
Among the children who had symptoms of LUTS and ADHD, 78\% (18/23) were full-term, and $22 \%$ (5/23) were premature (one with gestational age of less than 34 weeks) $(\mathrm{p}=0.6)$.

\section{DISCUSSION}

The present study demonstrated that children with ADHD have 2.3 times more chance of presenting LUTS, and that the most common voiding symptom in this population is urgency. The overall prevalence of ADHD symptoms in this study was in accordance to that previously reported. A recent review showed variability in the worldwide prevalence of ADHD symptoms around 5 to 29\% in community samples of children and adolescents. This variability in the prevalence of ADHD was attributed to methodological differences between the studies, specifically in the diagnostic criteria and sources of information between different countries (3). The observance of specific behaviors in various settings remains the most successful method for diagnosing $\operatorname{ADHD}(1,3)$. Although there are differences in particular areas of the brain and a high estimate of heritability (about $76 \%$ ), no test (neuroimaging or neurotransmitters) or genetic pattern is necessary or enough for the diagnosis of the disorder (1). Regarding ADHD

Figure 3 - Prevalence of Attention-Deficit Hyperactivity Symptoms (ADHD) in Children and Adolescents with Lower Urinary Tract Symptoms (LUTS).

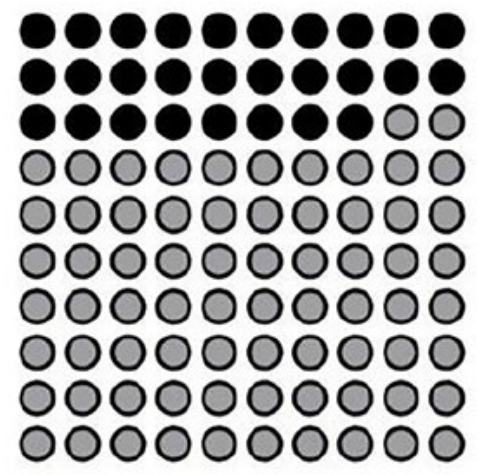

$\mathrm{ADHD}$
LUTS

No LUTS

O00000000

0000000000

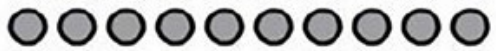

0000000000

0000000000

$\mathrm{OOOOOOOOOO}$

OOOOOOOOOO

0000000000

○०o०o०oo०o

no ADHD 
Table 1 - Description of Lower Urinary Tract Symptoms (LUTS) in Children and Adolescents with Attention-Deficit Hyperactivity (ADHD) Symptoms.

\begin{tabular}{|c|c|c|c|c|c|}
\hline Characteristics & \multicolumn{2}{|c|}{$\begin{array}{l}\text { ADHD symptoms } \\
\text { Mean } \pm \text { SD }\end{array}$} & \multicolumn{2}{|c|}{$\begin{array}{c}\text { No ADHD symptoms } \\
\text { Mean } \pm \text { SD }\end{array}$} & $p$ value \\
\hline Age & \multicolumn{2}{|c|}{$7.4 \pm 2.1$} & \multicolumn{2}{|c|}{$7.2 \pm 1.8$} & 0.8 \\
\hline Gender Male & \multicolumn{2}{|c|}{$59 \%$} & \multicolumn{2}{|c|}{$41 \%$} & 0.03 \\
\hline DVSS Total & \multicolumn{2}{|c|}{$10.2 \pm 4.85$} & \multicolumn{2}{|c|}{$4.9 \pm 2.95$} & 0.02 \\
\hline \multirow[t]{2}{*}{ Variables } & $\begin{array}{c}\text { Number } \\
\text { Patients (\%) }\end{array}$ & $\begin{array}{c}\text { Mean Score } \\
\pm S D\end{array}$ & $\begin{array}{c}\text { Number } \\
\text { Patients (\%) }\end{array}$ & $\begin{array}{c}\text { Mean Score } \\
\pm S D\end{array}$ & \\
\hline & Total 82 & & Total 330 & & \\
\hline 1. Daytime incontinence & $19(23.7)$ & $0.66 \pm 0.8$ & $58(17.5)$ & $0.62 \pm 0.7$ & 0.8 \\
\hline 2. Soaked underwear & $12(14.6)$ & $1.02 \pm 0.6$ & $36(10.9)$ & $0.9 \pm 0.4$ & 0.35 \\
\hline 3. Frequency of evacuation & $15(18.2)$ & $0.9 \pm 0.54$ & $69(20.9)$ & $0.7 \pm 0.55$ & 0.91 \\
\hline 4. Push bowel movements & $19(23.1)$ & $1.02 \pm 0.63$ & $60(18.1)$ & $0,85 \pm 0.35$ & 0.67 \\
\hline 5. Low urinary frequency & $11(13.2)$ & $0.86 \pm 1.2$ & $30(9.09)$ & $0.72 \pm 0.99$ & 0.3 \\
\hline 6. Holding maneuvers & $23(28.0)$ & $1.92 \pm 1.2$ & 38 (11.51) & $0.82 \pm 0.82$ & 0.02 \\
\hline 7. Urgency & $26(31.7)$ & $2.11 \pm 1.1$ & $28(8.48)$ & $0.93 \pm 0.74$ & 0.01 \\
\hline 8. Straining to void & $12(14.6)$ & $0.62 \pm 1.2$ & $23(6.96)$ & $0.74 \pm 1.1$ & 0.3 \\
\hline 9. Dysuria & $6(7.3)$ & $0.33 \pm 0.21$ & $28(8.48)$ & $0.22 \pm 0.44$ & 0.79 \\
\hline 10. Stressful events & $18(21.9)$ & $1.33 \pm 0.21$ & $79(23.9)$ & $0.91 \pm 0.17$ & 0.07 \\
\hline
\end{tabular}

Dysfunctional Voiding Symptom Score (DVSS); $p<0.05$

subtypes, $84 \%$ of our sample were identified with the combined subtype, also in agreement with other studies $(5,9,24)$.

In the present study, we have found a high prevalence of LUTS (28\%) in children and adolescents with ADHD symptoms. Individuals diagnosed with ADHD symptoms by MTA-SNAP-IV questionnaire were more likely to have LUTS, been the combined type the most frequent type, while hyperactivity/impulsivity type present in less than $10 \%$ of the patients with LUTS. Contrasting with our findings, Crimmins et al. showed that children with hyperactivity/impulsivity type ADHD is approximately 4.5 times more likely to have LUTS (25).

A longitudinal study found that early childhood externalizing (as impulsivity and hyperactivi- ty) and inattentive symptoms were associated with daytime urinary incontinence with increased odds of enuresis at 10 years and adolescents (26). Therefore, there is strong evidence in all age groups that ADHD is more common in patients with LUTS and vice versa. ADHD may be related to noradrenergic and dopaminergic pathways in the central nervous system, with decreased adrenergic activity affecting the lower urinary tract. Decrease in the $\beta$-adrenergic effect leads to contraction of detrusor, while an increase leads to relaxation of the detrusor (27). Regardless of the cause, it is a priority to address LUTS in patients of all age groups with neurodevelopmental conditions and vice-versa, using objective diagnostic tools including validated questionnaires $(6,28,29)$.

Two instruments validated for the Brazilian 
population to assess LUTS (14) and ADHD (19) were used. The mean DVSS total score in the group with ADHD symptoms (10.2) was significantly higher than in the group without ADHD (4.9). Similar results were found by Yang et al. (19) and Burgu et al. (28). The urgency scores raised by the question 7 in DVSS ("When your child wants to pee, can't he wait?") were significantly higher in the group with ADHD symptoms, similar to other studies $(19,28,30)$. We also found a high prevalence of holding maneuvers in our series, elicited by question 6 in DVSS ("Your child holds the pee by crossing his legs, crouching or dancing?"), which, to our knowledge, hasn't been demonstrated yet.

The assessment of bowel habits is recommended as an approach for children and adolescents with LUTS to diagnose BBD $(11,12)$. In this study, functional constipation was detected in 36\% of individuals with LUTS. These findings corroborate the results found by other authors $(12,30,31)$. However, ADHD did not increase the chance of having constipation in those presenting LUTS, different from the finding of Crimmins et al., 2003 (25), who found that children and adolescents with ADHD symptoms are significantly more likely to have functional constipation and fecal incontinence (32).

Regarding gestational age, 78\% of participants with LUTS and ADHD symptoms were full term. A recent study reported that prematurity is independently associated with the diagnosis of neurological development disorders. Also, it showed that 19.5\% of premature infants have ADHD, with a prevalence inversely proportional to gestational age (33). No studies were found showing an association between prematurity and LUTS.

This study has some limitations. Due to its configuration and design, the patient teacher's report on the MTA-SNAP-IV data was not included, which could increase its screening power (9). Also, the instrument's application was not repeated, which would be important for consistency results. We seek to minimize this limitation with the appropriate training of professionals who applied the instruments during outpatient care. In addition, it was not possible to provide information on the causal links between the two conditions, due to the cross-sectional nature of the study. It is important to state that all study subjects were recruited from a general pediatric clinic. Therefore, urofluxometry with electromyography and voiding diary were not obtained.

On the other hand, some features of this study may increase the strength of our findings, such as sample size and the use of standardized questionnaires. Most studies examine risk factors for nocturnal enuresis, with very few studies examining daytime voiding symptoms.

\section{CONCLUSION}

Children and adolescents, recruited in a general pediatric outpatient clinic, with ADHD symptoms are 2.3 times more likely to have LUTS. The combined type of ADHD was the most commonly associated with LUTS. Urgency and holding maneuvers were most prevalent symptoms in children and adolescents with ADHD symptoms. These findings support that all children with ADHD should be addressed for LUTS and vice versa.

\section{CONFLICT OF INTEREST}

None declared.

\section{REFERENCES}

1. Wolraich ML, Chan E, Froehlich T, Lynch RL, Bax A, Redwine ST, et al. ADHD Diagnosis and Treatment Guidelines: A Historical Perspective. Pediatrics. 2019; 144:e20191682.

2. Levelink B, Feron FJM, Dompeling E, van Zeben-van de Aa DMCB. Children With ADHD Symptoms: Who Can Do Without Specialized Mental Health Care? J Atten Disord. 2020; 24:104-12.

3. Posner J, Polanczyk GV, Sonuga-Barke E. Attention-deficit hyperactivity disorder. Lancet. 2020; 395:450-62.

4. Austerman J. ADHD and behavioral disorders: Assessment, management, and an update from DSM-5. Cleve Clin J Med. 2015; 82 (11 Suppl 1):S2-7.

5. Danielson ML, Bitsko RH, Ghandour RM, Holbrook JR, Kogan MD, Blumberg SJ. Prevalence of Parent-Reported ADHD Diagnosis and Associated Treatment Among U.S. Children and Adolescents, 2016. J Clin Child Adolesc Psychol. 2018; 


\section{7:199-212}

6. von Gontard A, Vrijens D, Selai C, Mosiello G, Panicker J, van Koeveringe G, et al. Are psychological comorbidities important in the aetiology of lower urinary tract dysfunctionICI-RS 2018? Neurourol Urodyn. 2019; 38(Suppl 5):S8-S17.

7. Catalá-López $F$, Ridao M, Núñez-Beltrán $A$, Gènova-Maleras $\mathrm{R}$, Alonso-Arroyo A, Aleixandre-Benavent $\mathrm{R}$, et al. Prevalence and comorbidity of attention deficit hyperactivity disorder in Spain: study protocol for extending a systematic review with updated meta-analysis of observational studies. Syst Rev. 2019; 8:49.

8. Bussing R, Fernandez M, Harwood M, Wei Hou, Garvan CW, Eyberg SM, et al. Parent and teacher SNAP-IV ratings of attention deficit hyperactivity disorder symptoms: psychometric properties and normative ratings from a school district sample. Assessment. 2008; 15:317-28.

9. Costa DS, de Paula JJ, Malloy-Diniz LF, Romano-Silva MA, Miranda DM. Parent SNAP-IV rating of attention-deficit/ hyperactivity disorder: accuracy in a clinical sample of ADHD, validity, and reliability in a Brazilian sample. J Pediatr (Rio J). 2019; 95:736-43.

10. Austin PF, Bauer SB, Bower W, Chase J, Franco I, Hoebeke $P$, et al. The standardization of terminology of lower urinary tract function in children and adolescents: Update report from the standardization committee of the International Children's Continence Society. Neurourol Urodyn. 2016; 35:471-81.

11. Nevéus T, Fonseca E, Franco I, Kawauchi A, Kovacevic L, Nieuwhof-Leppink A, et al. Management and treatment of nocturnal enuresis-an updated standardization document from the International Children's Continence Society. J Pediatr Urol. 2020; 16:10-19.

12. Vaz GT, Vasconcelos MM, Oliveira EA, Ferreira AL, Magalhães $P G$, Silva FM, et al. Prevalence of lower urinary tract symptoms in school-age children. Pediatr Nephrol. 2012; 27:597-603.

13. Farhat W, Bägli DJ, Capolicchio G, O'Reilly S, Merguerian PA, Khoury A, McLorie GA. The dysfunctional voiding scoring system: quantitative standardization of dysfunctional voiding symptoms in children. J Urol. 2000; 164 (3 Pt 2):1011-5.

14. Calado AA, Araujo EM, Barroso U Jr, Netto JM, Filho $M Z$, Macedo A Jr, et al. Cross-cultural adaptation of the dysfunctional voiding score symptom (DVSS) questionnaire for Brazilian children. Int Braz J Urol. 2010; 36:458-63.

15. von Gontard A, Equit M. Comorbidity of ADHD and incontinence in children. Eur Child Adolesc Psychiatry. 2015; 24:127-40.

16. Niemczyk J, Equit M, Hoffmann L, von Gontard A.
Incontinence in children with treated attention-deficit/ hyperactivity disorder. J Pediatr Urol. 2015; 11:141.e1-6.

17. Braga AANM, Veiga MLT, Ferreira MGCDS, Santana HM, Barroso U Jr. Association between stress and lower urinary tract symptoms in children and adolescents. Int Braz $J$ Urol. 2019; 45:1167-79.

18. Ma $Y$, Shen $Y$, Liu X. Association between enuresis and obesity in children with primary monosymptomatic nocturnal enuresis. Int Braz J Urol. 2019; 45:790-7.

19. Yang TK, Guo YJ, Chen SC, Chang HC, Yang HJ, Huang KH. Correlation between symptoms of voiding dysfunction and attention deficit disorder with hyperactivity in children with lower urinary tract symptoms. J Urol. 2012; 187:656-61.

20. Mattos P, Serra-Pinheiro MA, Rohde LA, Pinto D. A Brazilian version of the MTA-SNAP-IV for evaluation of symptoms of attention-deficit/hyperactivity disorder and oppositionaldefiant disorder. Rev. psiquiatr. Rio Gd. Sul 2006, 28, 2907.

21. Benninga MA, Faure C, Hyman PE, St James Roberts I, Schechter NL, Nurko S. Childhood Functional Gastrointestinal Disorders: Neonate/Toddler Gastroenterology. 2016: Online ahead of print.

22. Lane MM, Czyzewski DI, Chumpitazi BP, Shulman RJ. Reliability and validity of a modified Bristol Stool Form Scale for children. J Pediatr. 2011; 159:437-441.e1.

23. Jozala DR, Oliveira ISF, Ortolan EVP, Oliveira Junior WE, Comes GT, Cassettari VMG, et al. Brazilian Portuguese translation, cross-cultural adaptation and reproducibility assessment of the modified Bristol Stool Form Scale for children. J Pediatr (Rio J). 2019; 95:321-7.

24. Setyawan J, Fridman M, Grebla R, Harpin V, Korst LM, Quintero J. Variation in Presentation, Diagnosis, and Management of Children and Adolescents With ADHD Across European Countries. J Atten Disord. 2018; 22:911-23.

25. Crimmins CR, Rathbun SR, Husmann DA. Management of urinary incontinence and nocturnal enuresis in attentiondeficit hyperactivity disorder. J Urol. 2003; 170 (4 Pt 1):1347-50

26. Vasconcelos MMA, East P, Blanco E, Lukacz ES, Caballero G, Lozoff B, et al. Early Behavioral Risks of Childhood and Adolescent Daytime Urinary Incontinence and Nocturnal Enuresis. J Dev Behav Pediatr. 2017; 38:736-42.

27. Ölçücü MT, Kiliç HT, Yildirim K, Ateș F. Effects of methylphenidate on the lower urinary tract in patients with attention deficit hyperactivity disorder and without voiding dysfunction. J Pediatr Urol. 2020; 16:351.e1- 
351.e6.

28. Burgu B, Aydogdu 0, Gurkan K, Uslu R, Soygur T. Lower urinary tract conditions in children with attention deficit hyperactivity disorder: correlation of symptoms based on validated scoring systems. J Urol. 2011; 185:663-8.

29. Bastos JM Netto, Rondon AV, de Lima GRM, Zerati M Filho, Schneider-Monteiro ED, Molina CAF, et al. Brazilian consensus in enuresis-recomendations for clinical practice. Int Braz J Urol. 2019; 45:889-900.

30. Araújo FR, Almeida Vasconcelos MM, Kummer MA, Oliveira EA, Lima EM. Prevalence of lower urinary tract symptoms in children and adolescents diagnosed with attention deficit hyperactivity disorder. Revista Médica de Minas Gerais. 2016, 26. [Internet]. Available at. <http:// www.rmmg.org/artigo/detalhes/1982>

31. de Abreu GE, Dias Souto Schmitz AP, Dourado ER, Barroso U Jr. Association between a constipation scoring system adapted for use in children and the dysfunctional voiding symptom score in children and adolescents with lower urinary tract symptoms. J
Pediatr Urol. 2019; 15:529.e1-529.e7.

32. McKeown C, Hisle-Gorman E, Eide M, Gorman GH, Nylund $\mathrm{CM}$. Association of constipation and fecal incontinence with attention-deficit/hyperactivity disorder. Pediatrics. 2013; 132:e1210-5.

33. Soncini TCB, Belotto GA, Diaz AP. Association Between Prematurity and Diagnosis of Neurodevelopment Disorder: $A$ Case-Control Study. J Autism Dev Disord. 2020; 50:145-52.

\section{Correspondence address:}

Flávia Cristina de Carvalho Mrad, MD Departamento de Pediatria, Unidade de Nefrologia, Universidade Federal de Minas Gerais, Avenida Alfredo Balena, no 190 Belo Horizonte, Minas Gerais. 30130-100, Brasil E-mail: flaviacarvalhomrad@gmail.com

\section{APPENDIX}

Appendix 1 - Diagnostic Rome IV Criteria for Functional Constipation adapted from Benninga et al. (21).

Must include 1 month of at least 2 of the following in infants up to 4 years of age:

1. Two or fewer defecations per week

2. History of excessive stool retention

3. History of painful or hard bowel movements

4. History of large-diameter stools

5. Presence of a large fecal mass in the rectum

In toilet-trained children, the following additional criteria may be used:

6. At least 1 episode/ week of incontinence after the complete toilet training process

7. History of large-diameter stools that may obstruct 
Appendix 2 - Modified Bristol Stool Form Scale for Children adapted from Lane et al. (22).

\begin{tabular}{|l|l|}
\hline 1 & $\begin{array}{l}\text { Separate hard lumps, like nuts } \\
\text { (hard to pass) }\end{array}$ \\
\hline 3 & $\begin{array}{l}\text { Sausage-shaped but lumpy } \\
\text { Like a sausage or snake, smooth }\end{array}$ \\
\hline 4 & $\begin{array}{l}\text { Fluffy pieces with ragged edges, a } \\
\text { mushy stool }\end{array}$ \\
\hline 5 & Watery, no solid pieces. \\
\hline
\end{tabular}

